\title{
Age as a Factor Influencing Diversity of Commensal E. coli Microflora in Pigs
}

\author{
EWA BOK ${ }^{\star}$ JUSTYNA MAZUREK, PAWEŁ PUSZ, MICHAŁ STOSIK \\ and KATARZYNA BALDY-CHUDZIK \\ Department of Molecular Biology, Faculty of Biological Sciences \\ University of Zielona Góra, Zielona Góra, Poland
}

Received 4 August 2012, accepted 9 April 2013

\begin{abstract}
Commensal, intestinal E. coli microflora plays a role in maintenance of intestinal balance of the host, is responsible for defending against pathogenic E. coli. This study encompasses the analysis of BOX-PCR fingerprinting patterns, phylogenetic grouping and virulence genes prevalence among commensal E. coli isolates derived from healthy pigs. Altogether, 274 unique E. coli isolates were identified, 110 from weaned piglets (Piglets I and Piglets II) and 164 from adult sows (Sows I and Sows II). BOX-PCR analysis distinguished isolates from pigs in different age and indicated that during maturation the changes in E. coli microflora occurred. Phylogenetic grouping revealed significant differences between distribution of four phylogenetic groups among isolates derived from piglets and sows. In phylogenetic structure of isolates from the piglets group B1 prevailed significantly, while among isolates derived from the sows the majority of them were classified into phylogenetic group A. The identification of 17 virulence factors in E. coli isolates derived from healthy pigs was performed. Three of 13 intestinal (escV, ehxA, estII) and four extra-intestinal virulence genes (VGs) (hlyA, fimH, papA, sfaS) were detected in the porcine isolates. The percentage of VGs positive isolates among piglets is higher than among sows, moreover, the VGs occurring in $E$. coli isolates from piglets revealed greater diversity than that detected among isolates from sows.
\end{abstract}

Key words: BOX-PCR fingerprinting, commensal E. coli, healthy pigs, phylogenetic grouping, virulence genes profiles

\section{Introduction}

Piglets are born with sterile gastrointestinal tract, but during the next few hours their guts are colonized by many different microorganisms, which probably derive from skin, teats and feces of the dams (Arbuckle, 1968; Bertschinger et al., 1988). Among the earliest bacteria colonizing the gastrointestinal tract of piglets are E. coli (Drasar and Barrow, 1985) considered to be harmless commensals of mammals (Selander et al., 1987). Intestinal population of $E$. coli of pigs was described as very diverse and dynamic (Katouli et al., 1995). Factors such as weaning, age or diet of pigs are reported to be important for differentiation and changes in E. coli population (Hinton et al., 1985).

Most strains of E. coli are natural components of healthy gut flora (Hartl and Dykhuizen, 1984), but some strains can be a cause of either intestinal or extraintestinal disease (Kaper et al., 2004). Diarrheas in pigs are often associated with infections by pathogenic E. coli. Enterotoxigenic Escherichia coli (ETEC) is the most common cause of neonatal, pre- and postweaning diarrhea among piglets and therefore is responsible for economic losses in pig production (Straw et al., 1999; Frydendahl, 2002).

Weaning is a stressful situation for young piglets, it is connected with separation from the sow, change in diet from milk to solid food and with mixing of litters resulting in environmental instability (Spencer and Howell, 1989). It is believed that a highly diverse spectrum of commensal E. coli in the intestinal tract is responsible for defending against pathogenic E. coli (Kuhn et al., 1993). However, little is still known about the occurrence, individuality, phylogeny and dynamics of commensal E. coli isolates from food-producing animal of different age.

Pathogenic E. coli strains carry and express virulence genes such as adhesins, hemolysins or enterotoxins. Definite pathotypes and serotypes have a specific set of virulence genes that are crucial for infection and mechanisms of pathogenicity (Kaper et al., 2004). On the other hand, commensal E. coli can possess some virulence genes (Chapman etal., 2006; Wu etal., 2007). However, the presence of one or a few virulence genes does not determine the pathogenicity status of the strain until that strain has gained the appropriate

\footnotetext{
* Corresponding author: E. Bok, Department of Molecular Biology, Faculty of Biological Sciences, University of Zielona Góra, Monte Cassino St. 21b, 65-561 Zielona Góra, Poland; phone: + 486832873 33, fax: +48 6832873 21, e-mail: e.bok@wnb.uz.zgora.pl
} 
combination of virulence genes to cause the disease (Gilmore and Ferretti, 2003).

The goal of the present study was to determine if the age of healthy pigs has an influence on the genetic diversity of commensal E. coli isolates. The clonal relationships between isolates were characterized using BOXPCR fingerprinting method, additionally phylogenetic structure was assigned. The purpose of this study was also to determine the occurrence of virulence genes among commensal E. coli isolates from healthy pigs.

\section{Experimental}

\section{Materials and Methods}

Sample collection, isolation and identification of Escherichia coli strains. Fresh fecal samples were collected from healthy pigs (two groups of weaning piglets and two groups of sows) living in one farm. The samples were inoculated on agar $\mathrm{m}-\mathrm{FC}$ and incubated at $44^{\circ} \mathrm{C}$ for $24 \mathrm{~h}$. The blue colonies were placed on the MacConkey's agar and incubated at $37^{\circ} \mathrm{C}$ for $24 \mathrm{~h}$. Lactose-positive colonies were identified as a Escherichia coli by biochemical IMVC (indol, methyl-red-vogesproskauer, citrate) tests. Bacterial isolates were stored at $-80^{\circ} \mathrm{C}$ and non-passaged bacteria were used in all investigations.

DNA extraction. All isolates were prepared by inoculating of a single colony to $2 \mathrm{ml}$ of LB-medium and incubation at $37^{\circ} \mathrm{C}$ overnight. DNA was extracted using cell lysis method, $150 \mu \mathrm{l}$ overnight cultures were centrifuged, pellets were suspended in $25 \mu \mathrm{l}$ of sterile water and heated at $99^{\circ} \mathrm{C}$ for $10 \mathrm{~min}$. and transferred into ice for $5 \mathrm{~min}$. Cell debris was pelleted by centrifugation at $18000 \times \mathrm{g}$ for $4 \mathrm{~min}$. The supernatants were the source of DNA used in PCR reactions.

BOX-PCR fingrerprinting. The genotypic analyses of E. coli strains were carried out by BOX-A1R primer as described earlier (Versalovic et al., 1994). Amplification products were analyzed electrophoretically in $1.5 \%$ agarose gel stained with ethidium bromide and then washed in water. Gels were documented as TIFF files and analyzed with Fingerprintig II informatix software (BioRad). The similarity matrix was calculated on the basis of Jaccard similarity coefficient and dendrogram was generated by the unweighted pair group method with arithmetic mean analysis (UPGMA). The similarity relations were expressed as percentage. The similarity of BOX-PCR patterns of the orders of $80 \%$ was established as a cut-off value for determination of unique strains.

Phylogenetic grouping. The four major E. coli phylogenetic groups (A, B1, B2 and D) were determined as described previously (Clermont et al., 2000), by triplex
PCR of the chuA and $y j a A$ genes and the DNA fragment TspE4.C2.

Identification of unique isolates. Among isolates derived from the same probe and revealed $80 \%$ similarity of genomic patterns and simultaneously belonged to the same phylogenetic group only one was chosen as a representative.

Virulence genes determination. All isolates were screened for presence of 17 virulence genes: encoding toxins (stx1, stx2, eltA, estI, estII), hemolysins (hlyA, $e h x A$ ), nonfimbrial adhesin (escV) and fimbrial adhesins (fimH, papA, sfaS, faeG, fanC, fas A, fedA, f41, bfp B) associated with different $E$. coli pathotypes were identified by PCR. The primers and multiplex PCR conditions used were previously described (Chapman et al., 2006; Müller et al., 2006). Briefly PCR was performed on MJ Research ${ }^{\oplus}$ PTC-200 thermal cycler with a reaction volume of $25 \mu$ l. Reaction mixture contained: buffer solution (Finnzymes); $2,5 \mathrm{mM} \mathrm{MgCl}_{2}$ (Promega); 0,5 mM of each dNTP (Promega); 0,2 $\mu \mathrm{M}$ of each primer; $1 \mathrm{U}$ of DyNAzyme II polymerase (Finnzymes) and $3 \mu \mathrm{l}$ of DNA template. PCR reactions with template DNA of strain O157:H7 were used as a positive control. PCR mixtures without template DNA were used as a negative control.

DNA sequencing. PCR products of virulence factors were purified using PCR Isolate Kit (Bioline) and sequenced (Genomed) for gene verification. The nucleotide sequences of subject genes were compared with the target sequences in genetic sequence database - GenBank (NCBI).

Statistical analysis. The distributions of the phylogenetic groups of E. coli among the isolates and the distributions of the virulence genes were compared by the Chi-squared test (Sneath and Sokal, 1973).

\section{Results}

Similarity analysis of isolates. Based on the similarity of BOX-PCR genomic patterns with the use of UPGMA grouping method and the Jaccard similarity coefficient 274 unique E. coli isolates were identified (Table I).

The obtained dendrogram grouped 274 strains into 20 clusters (Table II) of a mutual similarity lower than $50 \%$. The particular clusters comprised different numbers of strains.

The created dendrogram of BOX-PCR patterns revealed the presence of 6 clusters formed only or in prevailed number by strains derived from piglets. Clusters VII, X, XII and XIV were formed only by strains derived from piglets. Moreover, cluster VII grouped strains from Piglets I and cluster X only from Piglets II. In clusters VIII and IX strains from piglets pre- 
Table I

Number of animals and identified unique E. coli isolates in subject groups

\begin{tabular}{|l|c|c|c|c|c|}
\hline \multicolumn{1}{|c|}{ Groups of animals/age } & $\begin{array}{c}\text { Piglets I/ } \\
6 \text { weeks }\end{array}$ & $\begin{array}{c}\text { Piglets II/ } \\
8 \text { weeks }\end{array}$ & $\begin{array}{c}\text { Sows I/ } \\
5 \text { months }\end{array}$ & $\begin{array}{c}\text { Sows II/ } \\
7 \text { months }\end{array}$ & Total \\
\hline Number of animals & 25 & 24 & 25 & 25 & 99 \\
\hline Number of E. coli isolates & 59 & 51 & 78 & 86 & 274 \\
\hline
\end{tabular}

Table II

Distribution of commensal E. coli isolates derived from pigs in different age among the similarity clusters of BOX-PCR dendrogram

\begin{tabular}{|l|c|c|c|c|c|}
\hline \multirow{2}{*}{$\begin{array}{c}\text { Similarity } \\
\text { clusters }\end{array}$} & \multicolumn{5}{|c|}{ Number of isolates derived from: } \\
\cline { 2 - 6 } & $\begin{array}{c}\text { Piglets } \\
\text { I } \\
(\mathrm{n}=59)\end{array}$ & $\begin{array}{c}\text { Piglets } \\
\text { II } \\
(\mathrm{n}=51)\end{array}$ & $\begin{array}{c}\text { Sows I } \\
(\mathrm{n}=78)\end{array}$ & $\begin{array}{c}\text { Sows II } \\
(\mathrm{n}=86)\end{array}$ & $\begin{array}{c}\text { Total number } \\
\text { of isolates } \\
(\mathrm{n}=274)\end{array}$ \\
\hline I & 1 & 1 & 5 & 5 & 12 \\
\hline II & 3 & - & 4 & 9 & 16 \\
\hline III & - & - & 17 & 11 & 28 \\
\hline IV & 1 & - & 10 & 11 & 22 \\
\hline V & 1 & - & 2 & 2 & 5 \\
\hline VI & 1 & - & 5 & 2 & 8 \\
\hline VII & 8 & - & - & - & 8 \\
\hline VIII & 14 & 20 & 1 & 1 & 36 \\
\hline IX & 12 & 11 & 2 & 1 & 26 \\
\hline X & - & 7 & - & - & 7 \\
\hline XI & - & - & 3 & 3 & 6 \\
\hline XII & 1 & 4 & - & - & 5 \\
\hline XIII & - & - & 2 & 2 & 4 \\
\hline XIV & 3 & 1 & - & - & 4 \\
\hline XV & 7 & 2 & 2 & 7 & 18 \\
\hline XVI & 1 & - & 14 & 10 & 25 \\
\hline XVII & - & - & 4 & 2 & 6 \\
\hline XVIII & - & - & 2 & 9 & 11 \\
\hline XIX & 1 & 1 & 3 & - & 5 \\
\hline XX & 1 & 1 & 1 & 2 & 5 \\
\hline Unclassified & 4 & 3 & 1 & 9 & 17 \\
\hline isolates & & & & & \\
\hline & & - & & & 2 \\
\hline
\end{tabular}

vailed significantly. 8 clusters gathered only or mainly the strains from sows. Clusters III, XI, XIII, XVII and XVIII grouped strains derived only from sows. Clusters I, IV and XVI encompassed strains from sows in great majority. There are also 6 clusters: II, V, VI, XV, XIX and XX formed by strains derived from both piglets and sows, which indicated the similarity of some isolates of the whole tested set.

Phylogenetic structure determination. A total number of 274 isolates were classified into one of the four main phylogenetic groups A, B1, B2 and D. The analysis of the genetic structure of E. coli isolates showed significant differences between strains derived from piglets and sows (Fig. 1). The four phylogenetic groups of E. coli were not uniformly distributed $(\mathrm{p}<0.001)$ among piglets and sows. Particularly the distribution of groups A and B1 in the groups of piglets and sows was statistically different $(\mathrm{p}<0.001)$. Among strains derived from piglets phylogenetic group B1 prevailed significantly $(48,2 \%)$, groups A and D were represented less frequently $(26.3 \%$ and $18.2 \%$ respectively), whereas strains belonging to group B2 were not numerous (7,3\%). The majority of strains derived from sows were classified into phylogenetic group A (54,3\%), isolates representing group $\mathrm{B} 1$ and $\mathrm{D}$ were less numerous ( $22 \%$ and $20, \%$ respectively), while group B2 were the smallest (3\%).

The analysis of the phylogenetic structure of E. coli strains among individual animals revealed significant difference between piglets and sows groups (Table III). There was no complete phylogenetic structure (A, B1, $\mathrm{B} 2$ and $\mathrm{D}$ ) among E. coli isolates in individual piglets. The majority of individuals have strains classified into one phylogenetic group (46.9\%), usually B1 or two groups (44.9\%), most frequently in combination $\mathrm{A}+\mathrm{B} 1$. Only $8.2 \%$ of individuals indicated the presence of isolates from three phylogenetic groups. However, among sows there was only one individual $(2 \%)$ with strains revealing complete phylogenetic structure. There were the comparable, numerous representation of sows with strains classified into two (48\%), usually in combination $\mathrm{A}+\mathrm{B} 1$, and three (48\%) phylogenetic groups, most frequently in combination $\mathrm{A}+\mathrm{B} 1+\mathrm{D}$. Considerably smaller percentage of adult individuals (2\%) revealed the presence of isolates which represented only one phylogenetic group (A) (Fig. 2).

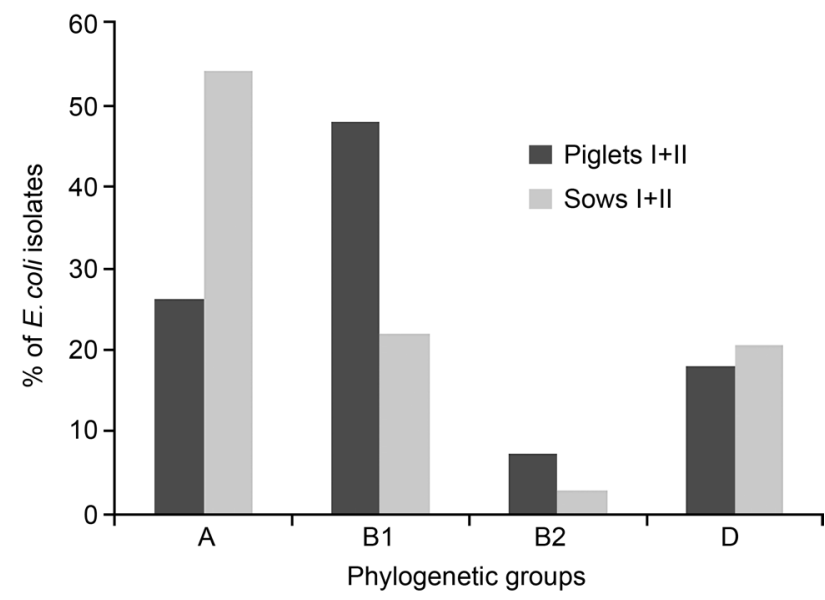

Fig. 1. The phylogenetic structure of $E$. coli isolates derived from piglets and sows 
Table III

Phylogenetic structure of E. coli isolates with reference to individual animals

\begin{tabular}{|c|c|c|c|c|c|c|c|c|c|c|}
\hline \multirow{3}{*}{$\begin{array}{l}\text { Phylogenetic } \\
\text { structure }\end{array}$} & \multicolumn{5}{|c|}{ Piglets I } & \multicolumn{5}{|c|}{ Piglets II } \\
\hline & \multirow[t]{2}{*}{$\mathrm{N}^{*}$} & \multicolumn{4}{|c|}{$\begin{array}{c}\text { Number of isolates } \\
n=59\end{array}$} & \multirow[t]{2}{*}{$\mathrm{N}^{*}$} & \multicolumn{4}{|c|}{$\begin{array}{l}\text { Number of isolates } \\
\qquad \mathrm{n}=51\end{array}$} \\
\hline & & $\mathrm{A}$ & B1 & B2 & $\mathrm{D}$ & & A & $\mathrm{B} 1$ & $\mathrm{~B} 2$ & $\mathrm{D}$ \\
\hline A & 4 & 5 & - & - & - & 1 & 2 & - & - & - \\
\hline B1 & 1 & - & 2 & - & - & 10 & - & 16 & - & - \\
\hline B2 & 1 & - & - & 2 & - & 1 & - & - & 1 & - \\
\hline $\mathrm{D}$ & 3 & - & - & - & 6 & 2 & - & - & - & 2 \\
\hline$A+B 1$ & 8 & 12 & 10 & - & - & 7 & 7 & 10 & - & - \\
\hline$A+D$ & 1 & 1 & - & - & 1 & 0 & - & - & - & - \\
\hline $\mathrm{B} 1+\mathrm{D}$ & 4 & - & 5 & - & 5 & 2 & - & 6 & - & 3 \\
\hline $\mathrm{A}+\mathrm{B} 1+\mathrm{D}$ & 1 & 1 & 1 & - & 1 & 0 & - & - & - & - \\
\hline $\mathrm{A}+\mathrm{B} 2+\mathrm{D}$ & 0 & - & - & - & - & 0 & - & - & - & - \\
\hline $\mathrm{A}+\mathrm{B} 1+\mathrm{B} 2$ & 1 & 1 & 1 & 2 & - & 0 & - & - & - & - \\
\hline $\mathrm{B} 1+\mathrm{B} 2+\mathrm{D}$ & 1 & - & 1 & 1 & 1 & 1 & - & 1 & 2 & 1 \\
\hline $\mathrm{A}+\mathrm{B} 1+\mathrm{B} 2+\mathrm{D}$ & 0 & - & - & - & - & 0 & - & - & - & - \\
\hline Total & 25 & 20 & 20 & 5 & 14 & 24 & 9 & 33 & 3 & 6 \\
\hline \multirow{3}{*}{$\begin{array}{l}\text { Phylogenetic } \\
\text { structure }\end{array}$} & \multicolumn{5}{|c|}{ Sows I } & \multicolumn{5}{|c|}{ Sows II } \\
\hline & $\mathrm{N}^{*}$ & \multicolumn{4}{|c|}{$\begin{array}{l}\text { Number of isolates } \\
\mathrm{n}=78\end{array}$} & $\mathrm{~N}^{*}$ & \multicolumn{4}{|c|}{$\begin{array}{l}\text { Number of isolates } \\
n=86\end{array}$} \\
\hline & & A & B1 & B2 & $\mathrm{D}$ & & A & B1 & B2 & $\mathrm{D}$ \\
\hline A & 0 & - & - & - & - & 2 & 2 & - & - & - \\
\hline B1 & 0 & - & - & - & - & 0 & - & - & - & - \\
\hline $\mathrm{B} 2$ & 0 & - & - & - & - & 0 & - & - & - & - \\
\hline $\mathrm{D}$ & 0 & - & - & - & - & 0 & - & - & - & - \\
\hline $\mathrm{A}+\mathrm{B} 1$ & 7 & 9 & 8 & - & - & 7 & 12 & 9 & - & - \\
\hline$A+D$ & 7 & 10 & - & - & 10 & 3 & 4 & - & - & 3 \\
\hline $\mathrm{B} 1+\mathrm{D}$ & 0 & - & - & - & - & 0 & - & - & - & - \\
\hline $\mathrm{A}+\mathrm{B} 1+\mathrm{D}$ & 10 & 12 & 12 & - & 13 & 10 & 18 & 11 & - & 10 \\
\hline $\mathrm{A}+\mathrm{B} 2+\mathrm{D}$ & 1 & 2 & - & 1 & 1 & 3 & 6 & - & 3 & 4 \\
\hline $\mathrm{A}+\mathrm{B} 1+\mathrm{B} 2$ & 0 & - & - & - & - & 0 & - & - & - & - \\
\hline $\mathrm{B} 1+\mathrm{B} 2+\mathrm{D}$ & 0 & - & - & - & - & 0 & - & - & - & - \\
\hline $\mathrm{A}+\mathrm{B} 1+\mathrm{B} 2+\mathrm{D}$ & 0 & - & - & - & - & 1 & 1 & 1 & 1 & 1 \\
\hline Total & 25 & 33 & 20 & 1 & 24 & 25 & 43 & 21 & 4 & 18 \\
\hline
\end{tabular}

$\mathrm{N}^{*}$ - number of individuals

Distribution of virulence genes. The identification of 17 virulence genes (VGs) in E. coli isolates derived from healthy pigs was performed. All E.coli isolates were analyzed for the presence of VGs characteristic for intestinal pathotypes (EHEC: stx1, stx2, escV, ehxA; EPEC: bfpB, escV, ehxA; ETEC: estI, estII, eltA, faeG, $f a n C, f a s A, f e d A, f 41)$ and that connected with extraintestinal pathotypes (ExPEC: hlyA, fim H, papA, sfaS). Three of 13 intestinal (escV, ehxA, estII) and four extraintestinal VGs ( $h l y A$, fim H, papA, sfaS) were detected in the porcine isolates. Among the VGs positive isolates, seven different VGs profiles were identified. There were one to three VGs in the single E. coli strain (Table IV). The analyzes also revealed the common occurrence of fim $\mathrm{H}$ gene in isolates derived from healthy pigs (not presented in table), as reported previously (Chapman et al., 2006; Wu et al., 2007).

There were significant differences between VGs profiles characteristic for isolates from piglets and sows. Only two profiles: escV and papA occurred simultaneously in isolates from piglets and sows groups. The profiles: $s f a S, e s c V+e h x A, h l y A+p a p A$ were assigned only to isolates from piglets and estII, escV+estII+papA were detected only among isolates from sows. The number of VGs positive isolates was statistically higher in the piglets then in the sows $(\mathrm{p}<0.001)$ and it amounts frequency $23.6 \%$ for piglets and $7.3 \%$ for sows. The diversity of virulence genes in the set of isolates from 


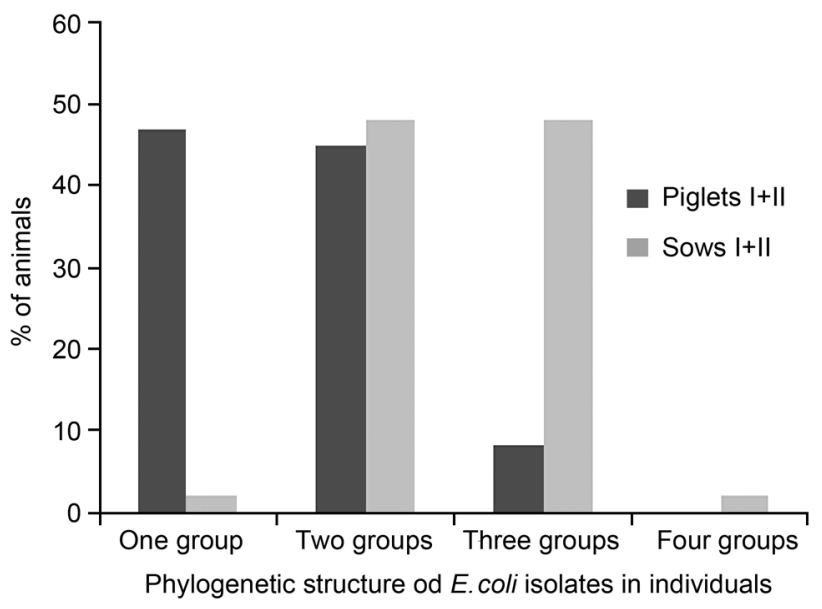

Fig. 2. The phylogenetic structure of E. coli isolates derived from individual animals with reference to number of phylogenetic groups

piglets was higher ( 5 different genes: escV, ehxA, hlyA, $p a p A, s f a S)$ than among isolates from sows ( 3 genes: escV, estII, papA). In both groups of animals the isolates with extra-intestinal virulence genes were more frequent (Table V), but the number of extra-intestinal VGs positive isolates was significantly higher in the piglets than in the sows $(\mathrm{p}<0.02)$. Among all piglets there were 11 isolates with $p a p A, 2$ with $s f a S$ and 2 with combination $h l y A+p a p A$ genes, summing up, this gives $15(13.6 \%)$. In the sows there were 7 isolates with papA and 1 with combination papA+esc $V+e s t I I$ genes, which gives 8 (4.9\%) altogether. The isolates that possess intestinal VGs were less frequent in both groups of animals, while the number of intestinal VGs positive strains was significantly higher in the piglets than in the sows $(\mathrm{p}<0,02)$. Among piglets 8 isolates with $e s c V$ gene and 3 with esc $V+e h x A$ genes were identified, it gives $11(10 \%)$ altogether. 1 isolate with $e s c V$, 3 with estII and 1 combination of esc V+estII+papA genes were detected in the sows group, summing up, this gives 5 (3\%). Moreover, VGs were carried by isolates of phylogenetic groups A, B1, B2 and D among piglets, while VGs positive isolates derived from sows were classified into groups A, B1 and D.

\section{Discussion}

The genetic diversity of clinical E. coli isolates derived from neonatal or postweaning diarrhea cases has beeen widely characterized in the literature (Wang et al., 2011; Bruant et al., 2009; Blanco et al., 2006), whereas data concerning the diversity of commensal, porcine E. coli are rather rare (Dixit et al., 2004; Schierack et al., 2006).

Table IV

The prevalence of VGs profiles among isolates from subject groups of pigs

\begin{tabular}{|l|c|c|c|c|c|c|}
\hline \multirow{2}{*}{ VGs profiles } & \multicolumn{5}{|c|}{ Number and phylogenetic group of isolates derived from } \\
\cline { 2 - 7 } & \multicolumn{4}{|c|}{ Piglets } & \multicolumn{3}{c|}{ Sows } \\
\cline { 2 - 7 } & $\begin{array}{c}\mathrm{I} \\
\mathrm{n}=59\end{array}$ & $\begin{array}{c}\mathrm{II} \\
\mathrm{n}=51\end{array}$ & $\begin{array}{c}\text { Total no. of VGs- } \\
\text { positive isolates } \\
\mathrm{n}=110\end{array}$ & $\begin{array}{c}\text { I } \\
\mathrm{n}=78\end{array}$ & $\begin{array}{c}\text { II } \\
\mathrm{n}=86\end{array}$ & $\begin{array}{c}\text { Total no. of VGs- } \\
\text { positive isolates } \\
\mathrm{n}=164\end{array}$ \\
\hline escV & $1 \mathrm{~A}, 4 \mathrm{~B} 1,3 \mathrm{D}$ & - & 8 & - & $1 \mathrm{~A}$ & 1 \\
\hline estII & - & - & - & $1 \mathrm{~A}$ & $1 \mathrm{~A}, 1 \mathrm{D}$ & 3 \\
\hline papA & $2 \mathrm{~B} 1$ & $6 \mathrm{~B} 1,2 \mathrm{~B} 2,1 \mathrm{D}$ & 11 & $1 \mathrm{~B} 1,1 \mathrm{D}$ & $3 \mathrm{~B} 1,2 \mathrm{D}$ & 7 \\
\hline sfaS & $2 \mathrm{~B} 2$ & - & 2 & - & - & - \\
\hline escV, ehxA & $1 \mathrm{~B} 2$ & $2 \mathrm{D}$ & 3 & - & - & - \\
\hline hlyA, papA & - & $1 \mathrm{~B} 1,1 \mathrm{~B} 2$ & 2 & - & - & - \\
\hline escV, estII, papA & - & - & - & - & $1 \mathrm{D}$ & 1 \\
\hline Total no. of VGs-positive isolates (\%) & $13(22)$ & $13(25,5)$ & $26(23,6)$ & $3(3,8)$ & $9(10,5)$ & $12(7,3)$ \\
\hline
\end{tabular}

Table V

The prevalence of intestinal and extra-intestinal VGs among isolates from subject groups of pigs

\begin{tabular}{|c|c|c|c|c|c|c|}
\hline \multirow{3}{*}{ Virulence genes } & \multicolumn{6}{|c|}{ Number of isolates with virulence genes (\%) } \\
\hline & \multicolumn{3}{|c|}{ Piglets } & \multicolumn{3}{|c|}{ Sows } \\
\hline & $\begin{array}{c}\mathrm{I} \\
\mathrm{n}=59\end{array}$ & $\begin{array}{c}\text { II } \\
n=51\end{array}$ & $\begin{array}{c}\text { Total } \\
\mathrm{n}=110\end{array}$ & $\begin{array}{c}\mathrm{I} \\
\mathrm{n}=78\end{array}$ & $\begin{array}{c}\mathrm{II} \\
\mathrm{n}=86\end{array}$ & $\begin{array}{c}\text { Total } \\
\mathrm{n}=164\end{array}$ \\
\hline Intestinal (escV, ehxA, estII) & $9(15,3)$ & $2(3,9)$ & $11(10)$ & $1(1,3)$ & $4(4,7)$ & $5(3)$ \\
\hline Extra-intestinal (hlyA, papA, sfaS) & $4(6,8)$ & $11(21,6)$ & $15(13,6)$ & $2(2,6)$ & $6(7)$ & $8(4,9)$ \\
\hline Total (\%) & $13(22)$ & $13(25,5)$ & $26(23,6)$ & $3(3,8)$ & $9(10,5)$ & $12(7,3)$ \\
\hline
\end{tabular}


It seems very important to gain more detailed knowledge about genetic structure and possession of VGs among commensal isolates derived from pigs in different age, this may help understand why young piglets are often susceptible to diarrhea caused by pathogenic E. coli. This study encompassed the complex analysis of genetic diversity of commensal E. coli isolates derived from healthy, weaned (Piglets I and Piglets II) and finished grow pigs (Sows I and Sows II). The diversity of porcine E. coli isolates was expressed by polymorphism of BOX-PCR patterns, phylogenetic grouping, phylogenetic structure of isolates among individual animals and identification of virulence profiles.

BOX-PCR fingerprinting analysis has shown closer relationship between strains grouped in common clusters and simultaneously the differences between isolates derived from piglets and sows which grouped mainly in separate clusters. In general, analysis of polymorphism of genomic patterns distinguished strains from pigs in different age and indicated that during growing up the changes in E. coli microflora occurred.

Phylogenetic grouping revealed significant differences between distribution of four phylogenetic groups among isolates derived from piglets and sows. These results confirm earlier reports concerning the phylogenetic structure of isolates from healthy piglets with predominance of group B1 (Bibbal et al., 2009). It was also previously described (Cortés et al., 2010; Carlos et al., 2010) that the most commensal strains in sows belonged to group A. In present studies differences between phylogenetic structure of isolates from the particular individual animals were analyzed. Among isolates from individual piglets the simple phylogenetic structure consisted of one or two predominating groups. A more complex phylogenetic structure, encompassing two or three groups, was characteristic for the individual sows.

BOX-PCR fingerprinting as well as phylogenetic grouping analysis indicated on significant genomic diversity between isolates derived from piglets and sows, but on the another level. Genomic patterns and phylogenetic structure diversities do not correspond to each other but increase genomic characterization of tested isolates. Both these analyses confirmed that the age of the host has a considerable influence on the genomic diversity of isolates. In the present studies the analysis of phylogenetic structure of isolates in particular individuals revealed lower diversity in piglets than in sows. It was stated previously by another method (biochemical fingerprinting) that among young animals E. coli flora is not diverse (Katouli et al., 1995).

This study encompasses the analysis of occurrence of $17 \mathrm{VGs}$ among commensal, porcine isolates. Among piglets, isolates carrying genes associated with the EPEC/EHEC pathotypes (esc $V$ and $e s c V+e h x A$ ) as well as these characteristic for ExPEC (papA, sfaS and $h l y A+p a p A$ ) were identified. The occurrence of various combinations of these genes and the same virulence profiles among strains belonging to different phylogenetic groups is consistent with horizontal transfer of genetic elements harboring these VGs. In sows isolates, which carry VGs associated with profile characteristic for ETEC pathotypes (estII gene), and for ExPEC (papA gene), were identified. Moreover, among sows the isolate possesses the profile escV+estII+papA which is the combination of genes characteristic for the EPEC/EHEC, ETEC and ExPEC pathotypes were also detected. The appearance of such a combination and occurrence of these genes among isolates belonged to separate phylogenetic groups confirmed that prevalence of these genes is connected with horizontal transfer. Two profiles: escV and papA occurred simultaneously in isolates from piglets and sows groups and some isolates carrying these genes belong to the same phylogenetic groups, which indicated the possibility of transmission of these isolates from sows to their litters.

It was reported (Johnson and Stell, 2000) that strains belonging to phylogenetic groups $\mathrm{B} 2$ and $\mathrm{D}$ and carry $h l y A$ and papA genes cause extra-intestinal disease. One of the identified VGs positive isolates, has a combination of $h l y A+p a p A$ and belongs to $\mathrm{B} 2$ group.

Significant differences between isolates derived from piglets and sows were showed. The percentage of VGs positive isolates among piglets is higher than among sows, moreover, also the VGs occurring in E. coli isolates from piglets revealed greater diversity than those detected among isolates from sows. These results indicated that with the evolving of the host organisms there appeared some changes in the genetic structure of commensal E. coli. Piglets during growing up lose strains which constitute a reservoir of the virulence genes, therefore among sows VGs positive isolates were detected less frequently but still maintained.

In this study comparative analysis of fingerprinting genomic patterns, phylogenetic grouping and virulence profiles of commensal porcine isolates, in the aspect of the age of pigs, were carried out. This complex analysis confirmed, as was previously partially reported (Katouli et al., 1995), that age is an important factor influencing the diversity of commensal microflora among pigs. It was stated that simple phylogenetic structure of commensal E. coli derived from piglets occurred in pair with more complex genetic diversity among separate phylogenetic groups.

There is also some evidence that weaning is the key moment in the piglets life, it is connected with stress during separation from the dam and with changes in diet from milk to solid food, which cause environmental instability (Spencer and Howell, 1989). It is obvious that environmental stabilization and physiological 
development of the intestinal tract influenced the increase of the diversity of the natural microflora (Pielou, 1975), as the piglets aged. The great diversity of E. coli strains colonizing the gut epithelium guarantee a competitive barrier against enteric pathotypes (Dixit et al., 2004; Wu et al., 2007).

\section{Acknowledgments}

This study was supported by the Ministry of Science and Higher Education grant N304412538.

\section{Literature}

Arbuckle J.B.R. 1968. The distribution of certain Escherichia coli strains in pigs and their environment. Br. Vet. J. 124: 152-159.

Bertschinger, H.W., V. Eng and P. Wegmann. 1988. Relationship between coliform contamination of floor and teats and the incidence of puerperal mastitis in two types of farrowing accommodations, pp. 86-88. In: Ekesbo I. (eds). Proceedings of the $6^{\text {th }}$ International Congress on Animal Hygiene. Swedish University of Agricultural Science, Skara, Sweden.

Bibbal D., V. Dupouy, M.F. Prère, P.L. Toutain and A. BousquetMélou. 2009. Relatedness of Escherichia coli strains with different susceptibility phenotypes isolated from swine feces during ampicillin treatment. Appl. Environ. Microbiol. 75: 2999-3006.

Blanco M., L. Lazo, J.E. Blanco, G. Dahbi, A. Mora, C. López, E.A. González and J. Blanco. 2006. Serotypes, virulence genes, and PFGE patterns of enteropathogenic Escherichia coli isolated from Cuban pigs with diarrhea. Int. Microbiol. 9: 53-60.

Bruant G., Y. Zhang, P. Garneau, J. Wong, C. Laing, J.M. Fairbrother, V.P. Gannon and J. Harel. 2009. Two distinct groups of porcine enteropathogenic Escherichia coli strains of serogroup O45 are revealed by comparative genomic hybridization and virulence gene microarray. BMC Genomics. 26;10:402.

Carlos C., M.M. Pires, N.C. Stoppe, E.M. Hachich, M.I. Sato, T.A. Gomes, L.A. Amaral and L.M. Ottoboni. 2010. Escherichia coli phylogenetic group determination and its application in the identification of the major animal source of fecal contamination. BMC Microbiol. 1;10:161.

Chapman T., X.Y. Wu, I. Barchia, K. Bettelheim, S. Driesen, D. Trott, M. Wilson and J. Chin. 2006. A comparison of virulence gene profile between $E$. coli strains isolated from healthy and diarrheic swines. Appl. Environ. Microbiol. 72: 4782-4795.

Clermont O., S. Bonacorsi and E. Bingen. 2000. Rapid and simple determination of the Escherichia coli phylogenetic group. Appl Environ Microbiol. 66: 4555-4558.

Cortés P., V. Blanc, A. Mora, G. Dahbi, J.E. Blanco, M. Blanco, C. López, A. Andreu, F. Navarro, M.P. Alonso and others. 2010. Isolation and characterization of potentially pathogenic antimicrobial-resistant Escherichia coli strains from chicken and pig farms in Spain. Appl. Environ. Microbiol. 76: 2799-805.

Dixit S.M., M. D. Gordon, X.Y. Wu, T. Chapman, K. Kailasapathy and J. J. Chin. 2004. Diversity analysis of commensal porcine Escherichia coli - associations between genotypes and habitat in the porcine gastrointestinal tract. Microbiology 150: 1735-1740.

Drasar B. S. and P. A. Barrow. 1985. Intestinal microbiology, pp. 33-35. In: Neidhardt F. C. (eds). Cellular and molecular biology. ASM Press, Washington, D.C.
Frydendahl K. 2002. Prevalence of serogroups and virulence genes in Escherichia coli associated with postweaning diarrhea and edema disease in pigs and a comparison of diagnostic approaches. Vet. Microbiol. 85: 169-182.

Gilmore M. S. and J. J. Ferretti. 2003. The thin line between gut commensal and pathogen. Science 299: 1999-2002.

Hartl D.L. and D.E. Dykhuizen. 1984. The population genetics of Escherichia coli. Annu. Rev. Genet. 18: 31-68.

Hinton M., D.J. Hampson, E. Hampson and A.H. Linton. 1985. A comparison of the ecology of Escherichia coli in the intestine of healthy unweaned pigs and pigs after weaning. J. Appl. Bacteriol. 58: 471-478.

Johnson J.R. and A.L. Stell. 2000. Extended virulence genotypes of Escherichia coli strains from patients with urosepsis in relation to phylogeny and host compromise. J. Infect. Dis. 181: 261-272.

Kaper J.B., J.P. Nataro and H.L. Mobley. 2004. Pathogenic Escherichia coli. Nat. Rev. Microbiol. 2: 123-140.

Katouli M., A. Lund, P. Wallgren, I. Kuhn, O. Soderlind and R. Mollby. 1995. Phenotypic characterization of intestinal Escherichia coli of pigs during suckling, postweaning, and fattening periods. Appl. Environ. Microbiol. 61: 778-783.

Kuhn I., M. Katouli, A. Lund, P. Wallgren and R. Mollby. 1993. Phenotypic diversity and stability of the intestinal coliform flora in piglets during the first 3 months of age. Microb. Ecol. Health Dis. 6: 101-107.

Müller D., P. Hagedorn, S. Brast, G. Heusipp, M. Bielaszewska, A.W. Friedrich, H. Karch and M.A. Schmidt. 2006. Rapid identification and differentiation of clinical isolates of enteropathogenic Escherichia coli (EPEC), atypical EPEC, and Shiga toxin-producing Escherichia coli by a one-step multiplex PCR method. J. Clin. Microbiol. 44: 2626-2629.

Pielou E. 1975. Ecological diversity. Wiley Interscience, New York, N.Y.

Selander R.K., D.A. Caugant and T.S. Whittam. 1987. Genetic structure and variation in natural populations of Escherichia coli. In Escherichia coli and Salmonella Typhimurium, pp. 1625-1648. In: Neidhardt F.C. (eds). Cellular and molecular biology. ASM Press, Washington, D.C.

Schierack P., H. Steinrück, S. Kleta and W. Vahjen. 2006. Virulence factor gene profiles of Escherichia coli isolates from clinically healthy pigs. Appl. Environ. Microbiol. 72: 6680-6686.

Sneath P.H.A. and R.R. Sokal. 1973. Numerical Taxonomy. W.H. Freeman, San Francisco.

Spencer B.T. and P.G. Howell. 1989. Some husbandry factors influencing weaning stresses in piglets. J.S. Afr. Vet. Assoc. 60: 62-64.

Straw B.E., D.E. Dewey and M.R. Wilson. 1999. Differential diagnosis of swine diseases, pp. 41-59. In: Straw B.E., S. D'Allaire, W.L. Mengeling, and D.J. Taylor (eds). Diseases of swine. Iowa State University Press, Ames.

Versalovic J., M. Schneider, F.J. de Bruijn and J.R. Lupski. 1994. Genomic fingerprinting of bacteria using repetitive sequence-based polymerase chain reaction. Methods Mol. Cell. Biol. 5: 25-40.

Wang X.M., X.P. Liao, S.G. Liu, W.J. Zhang, H.X. Jiang, M.J. Zhang, H.Q. Zhu, Y. Sun, J. Sun, A.X. Li and Y.H. Liu. 2011. Serotypes, virulence genes, and antimicrobial susceptibility of Escherichia coli isolates from pigs. Foodborne Pathog. Dis. 8: 687-692.

Wu X.Y., T. Chapman, D.J. Trott, K. Bettelheim, T.N. Do, S. Driesen, M.J. Walker and J. Chin. 2007. Comparative analysis of virulence genes, genetic diversity, and phylogeny of commensal and enterotoxigenic Escherichia coli isolates from weaned pigs. Appl. Environ. Microbiol. 73: 83-91. 
